\title{
Imagens Descolonizadas ou Livres
}

Gilda $\operatorname{Vogt}^{1}$

O artista precisa fazer a Descolonização do próprio pensamento. Sobre esse conceito, li numa entrevista com o antropólogo Eduardo Viveiros de Castro (Lambert e Barcellos, 2012), onde ele comenta sobre a interação que deve existir entre a Antropologia, a Filosofia e a Psicologia, e que acredito que interagem com as Artes. Ele sugere que se deve fazer mais experimentos através da imaginação entre estas áreas diversas, e diz que todo indivíduo desenvolve seus estudos e pesquisas com naturalmente a tendência de estratificação, para garantir uma aceitação e um melhor entendimento aparente. Então, as novas buscas acabam desapercebidas e desnecessárias, e com muitos riscos envolventes, surgindo um vício protetor, mas que acaba sendo um engano, uma auto destruição, ou uma armadilha. A tendência de acomodação está sempre presente, acompanhando como proteção ou escudo imaginário. ${ }^{2}$

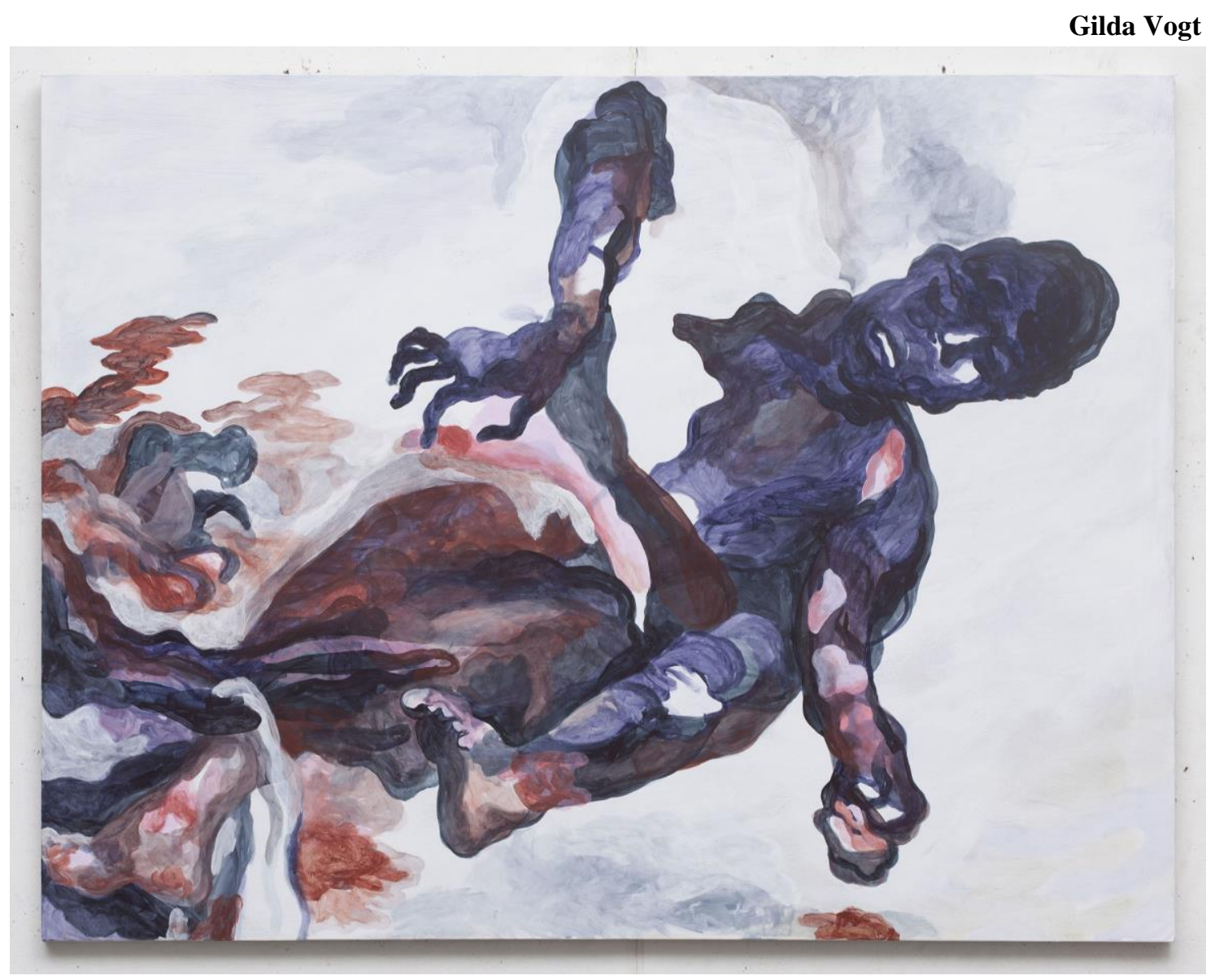

Manaus (Mãe dos Deuses), 2017

\footnotetext{
${ }^{1}$ Artista plástica, São Paulo, Brasil.

${ }^{2}$ Nota da Organizadora: Texto original especialmente convidado para compor a Sessão de Ensaios Queermuseu: Cartografias da Diferença na Arte Brasileira.
} 
Antes, enquanto fazia a pintura "Manaus", ilustrada aqui, encontrei um bom reforço sobre esse entendimento no livro "Relatar a si mesmo", da filósofa Judith Butler (2015), e que não canso de reler. Ela escreve sobre o raciocínio e o enfrentamento, e fala de como as manobras subjetivas são difíceis de serem bem conscientes, e de como o "Se Conhecer" inclui a "Reflexão com o Outro", com as incertezas nas tentativas que só se revelam depois do risco tomado. E de como a intuição parte desta questão artística não é tão palpável.

Acho que é preciso de certa consciência mais abrangente para perceber tudo isso. Entendo que os meus trabalhos são lances em coordenação com as emoções envolvidas, onde o medo e a insegurança fazem parte desta questão em processo e como forma de criatividade nos experimentos.

Conto com certas imagens que têm força e carregam revelando muitos significados e abrangem muitos aspectos, onde se podem fazer muitas livres associações. Entretanto, as regras e censuras psicológicas sempre acompanham os costumes e os pensamentos, e o fator antropológico abrange tudo isso.

O motivo ou tema do meu trabalho "Manaus: Mãe dos Deuses", onde está focado o massacre com a rebelião e a questão social de uma barbárie, que acabou sendo coincidentemente negada e invisível. E coincidiu com o fechamento da exposição!

Talvez a imagem nem seja tão evidente e nem acuse o fato tão declaradamente. Precisaria um tempo de escrutinação - que até eu mesma tive - no processo de entendimento do fato horrível, através da pequena foto do jornal, onde fui enxergando a triste notícia do início do ano, no dia 3 de janeiro de 2017.

A nossa consciência emocional não quer se envolver com esta reflexão dolorida e que, apesar disto, nos pertence. Me senti num Instituto Médico Legal enquanto pintava o quadro... Mesmo sendo esta uma visão do "Outro", é aí onde surge a minha Reflexão e o próprio modo de sentir, como um tipo de Identificação com o Estranho. 


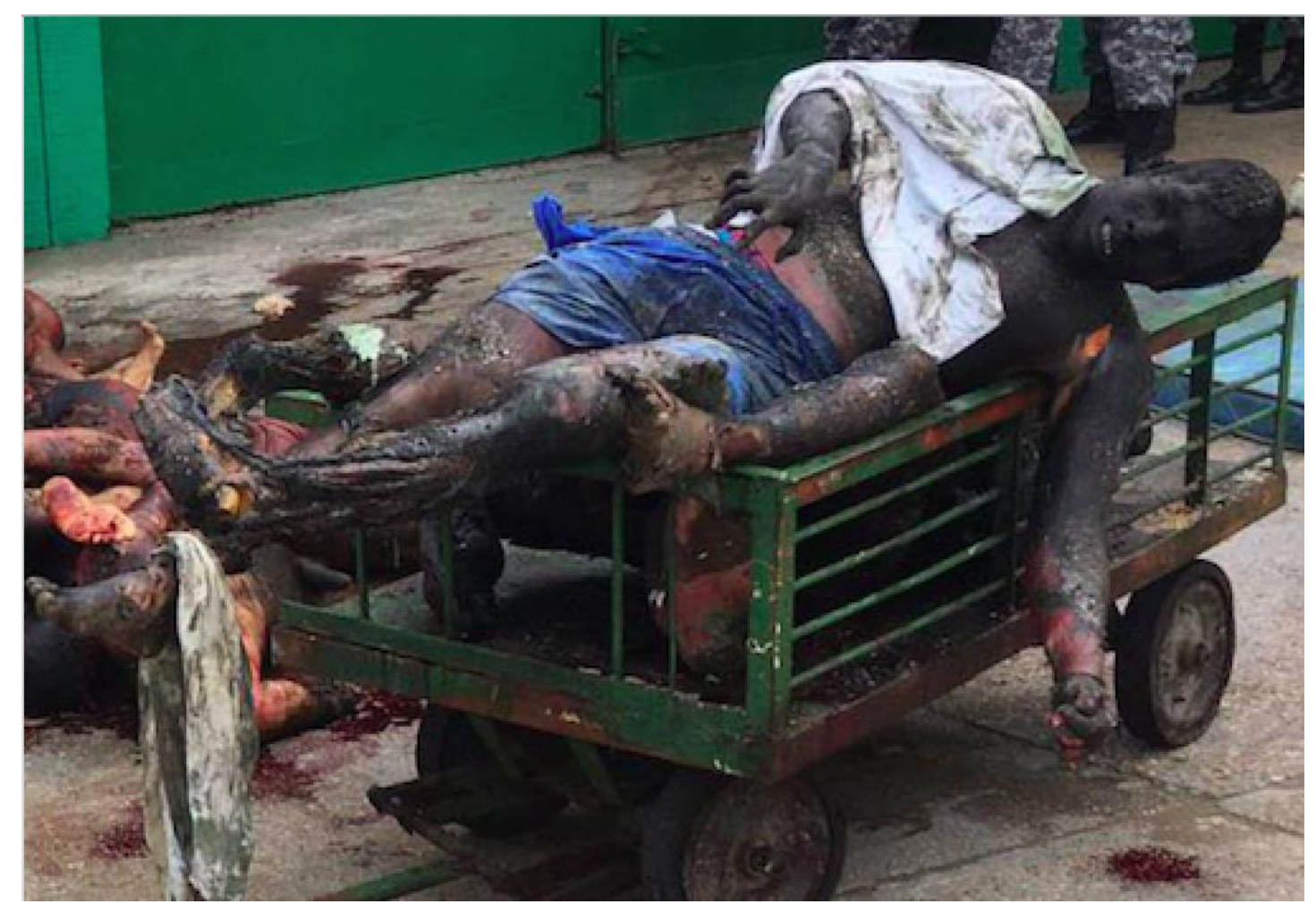

Print de tela de imagem retirada da Folha de São Paulo da matéria "Maior matança em presídios desde o Carandiru deixa 56 vítimas no AM", Caderno Cotidiano, edição de 03/01/2017.

Estes incidentes constantes e perseverantes em consequência da nossa organização social deficiente tão desigual, onde seres humanos são sacrificados, terminaram igualmente “censurados". E pela mesma forma de negação - como o fato se tornou invisível e deslocado. E essa conjuntura de descaso está sendo disseminada cada vez mais pelo Brasil inteiro, há anos se perpetuando, com o mesmo sentido abismal.

Isso tudo tão sério já foi identificado e parece que até o descuido foi assumido. Os acontecimentos ficam descartados, como os corpos destes seres humanos que estão sendo sacrificados no contex to do disfarce teatral brasileiro.

Aqui a minha Descolonização no sentido livre de conduta (Fidelis, 2014) vem como a tentativa de uma atitude de tocar neste assunto usando outro modo de enfrentamento, para poder reforçar a reflexão que normalmente ninguém gosta de encarar. Mas esta deveria ser constatada, se não fosse a pobreza cultural da censura onde justamente a liberdade foi vista com tanto preconceito, como se a atitude da curadoria fosse degenerada. Quando foi justo o contrário que motivou a intenção do Gaudêncio Fidelis, ao escolher obras diversas que carregam um conceito de "Novo Estranhamento", ao selecionar trabalhos para a exposição Queermuseu: cartografias da diferença na arte brasileira. 


\section{Bibliografia citada:}

BUTLER, Judith. Relatar a si mesmo: crítica da violência ética. Belo Horizonte: Autêntica Editora, 2015 (Filô).

FIDELIS, Gaudêncio. Gilda Vogt: uma retrospectiva. Porto Alegre: MARGS, 2014. p. 60. LAMBERT, Cleber; BARCELLOS, Larissa. Entrevista com Eduardo Viveiros de Castro. Primeiros estudos, São Paulo, n. 2, p. 251-267, 2012. 